\title{
Prim-O-glucosylcimifugin enhances the antitumour effect of PD-1 inhibition by targeting myeloid-derived suppressor cells
}

\footnotetext{
* Correspondence: 1120170411@mail.nankai.edu.cn

cheng.yang@nankai.edu.cn; tao.sun@nankai.edu.cn

tWanfeng Gao, Xiaoyun Zhang and Wendong Yang contributed equally to this work.

${ }^{1}$ State Key Laboratory of Medicinal Chemical Biology and College of Pharmacy, Nankai University, Haihe Education Park, 38 Tongyan Road, Tianjin 300353, China

Full list of author information is available at the end of the article such as regulatory T-lymphocytes (Tregs) and myeloidderived suppressor cells (MDSCs) [4-6].

MDSCs are abundant in the lymphoid organs of tumourbearing mice and patients. MDSCs mainly include polymorphonuclear MDSC (PMN-MDSC) and monocytic

cancer cells (4 T1), the overall response rates of PD-1/PDL1 inhibitors are only 5-30\%; in melanoma (B16-F10), tumour recurrence often occurs despite continuous treatment after the initial tumour subsides [2,3]. The limitation of immune checkpoint inhibitors may be mediated by the immunosuppressive tumour microenvironment, which mainly includes some immunosuppressive factors released by tumours and some infiltrating immunosuppressive cells, 
MDSC (M-MDSC) subpopulations. M-MDSCs are labelled as $\mathrm{CD} 11 \mathrm{~b}^{+} \mathrm{Ly}_{6 \mathrm{G}}{ }^{-} \mathrm{Ly}_{6} \mathrm{C}^{\text {high, }}$ and PMN-MDSCs are labelled

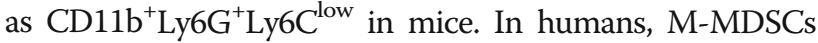
are labelled as HLA-DR ${ }^{-} \mathrm{CD} 11 \mathrm{~b}^{+} \mathrm{CD} 33^{+} \mathrm{CD} 14^{+}$, and PMNMDSCs are labelled as HLA-DR ${ }^{-} \mathrm{CD} 11 \mathrm{~b}^{+} \mathrm{CD} 33^{+} \mathrm{CD} 15^{+}$[7]. MDSCs respond to the stimulation of cancer-derived factors, such as granulocyte colony-stimulating factor (GCSF), interleukin-6 (IL-6) and granulocyte monocyte colony-stimulating factor (GM-CSF), through transcription factors STAT1, STAT3, STAT6 and NF-кB to proliferate and obtain immunosuppressive activity in bone marrow $[8$, 9]. Activated MDSCs are recruited to tumour sites through the actions of inflammatory factors (i.e., IL6 and IL1 $\beta$ ), PEG2, S1P and chemokines (i.e., CCL2) [10-12]. In the tumour sites, MDSCs form the immunosuppressive microenvironment by producing Arg-1, iNOS, IDO, NOX2 and immunosuppressive cytokines [13, 14], and MDSCs express a large amount of PD-L1 through the stimulation of hypoxia-inducible factor $1 \alpha$ (HIF1 $\alpha)$ and tumour-derived exosomes and eventually inhibit the activity of $\mathrm{T}$ cells $[15$, 16]. In addition, activated MDSCs in tumours could affect tumour remodelling and tumour angiogenesis by producing VEGF, basic fibroblast growth factor (bFGF), Bv8 and MMP9, thereby promoting tumour progression [17, 18]. Therefore, targeting MDSCs is a new cancer treatment strategy that could enhance the antitumour effects of PD-1/ PD-L1 inhibitors.

In the present study, we successfully screened prim-Oglucosylcimifugin (POG) as a PMN-MDSC inhibitor from the traditional Chinese Medicine library. In vitro and in vivo experiments showed that POG could inhibit the proliferation, metabolism and immunosuppressive ability of PMN-MDSCs, improve the tumour immunosuppressive microenvironment and generate a synergistic effect with PD-1 inhibitors in B16F10 and 4 T1 mouse tumour models. This finding suggested that POG is a sensitiser for PD-1 inhibitors.

\section{Materials and methods}

\section{Tissue processing and flow cytometry}

Bone marrow cells were flushed from the femurs and tibias with PBS with a syringe. The spleen samples were processed through mechanical dissociation, and tumour tissues were processed into single-cell suspensions by dissociating the tissues enzymatically for $1 \mathrm{~h}$ with $1 \mathrm{mg} / \mathrm{ml}$ type I collagenase (Sigma-Aldrich) in the presence of 50 units/mL DNase (Sigma-Aldrich). The cells were lysed with red blood cell lysis buffer and filtered with a $100 \mu \mathrm{m}$ membrane, further washed with $1 \%$ BSA in PBS and blocked by non-specific staining with Fc Block (anti-mouse CD16/32 mAb; BD Biosciences). The samples were then stained with fluorescenceconjugated antibodies against the surface markers CD45 (clone 30-F11, eBioscience), CD11b (clone M1/70, eBioscience), Ly6C (clone HK1.4, eBioscience), Ly6G (clone 1A8-Ly6g, eBioscience), CD3 (clone 145-2C11, eBioscience) and CD8 (clone 53-6.7, eBioscience) and detected using flow cytometry (LSR BD Fortessa).

\section{Cell sorting of PMN-MDSCs and T-lymphocytes}

The single-cell suspensions of the tumour, bone marrow and spleen samples were stained with fluorescence-conjugated antibodies against the surface markers CD11b, Ly6C, Ly6G, CD3 and CD8 for $30 \mathrm{~min}$ at $4{ }^{\circ} \mathrm{C}$. PMN-MDSCs and Tlymphocytes were then sorted through flow cytometry (BD ArialII). The sorted PMN-MDSCs were cultured in RPMI 1640 with $10 \%$ foetal bovine serum, $20 \mathrm{ng} / \mathrm{mL}$ recombinant GM-CSF (Recombinant CJ46, Novoprotein), $20 \mathrm{ng} / \mathrm{mL}$ IL6 (CG39, Novoprotein) and $50 \mu \mathrm{M}$ 2-mercaptoethanol (60-24-2, Biotech). The sorted T-lymphocytes were cultured in RPMI 1640 with $10 \%$ foetal bovine serum and stimulated with CD3 (clone 145-2C11, eBioscience) and CD28 antibodies (clone 37.51, eBioscience, $5 \mu \mathrm{g} / \mathrm{mL})$.

\section{PMN-MDSC isolation and proteomic analysis}

Bone marrow cells were harvested from naive C57BL6 mice and B16-F10 tumour-bearing mice and then processed into single-cell suspensions. Naive PMN-MDSCs and B16-F10 tumour-bearing PMN-MDSCs were sorted through flow cytometry. The sorted naive PMN-MDSCs and B16-F10 tumour-bearing PMN-MDSCs were then prepared for proteomics analysis. A fold change of more than 2 was defined as significantly different. Gene ontology (GO) analysis and KEGG enrichment analysis were performed using the DAVID database $[19,20]$. Protein-protein interaction networks were analysed with the STRING database [21].

\section{Screening PMN-MDSC inhibitors by molecular docking and weight calculation of docking scores}

To screen the natural inhibitors of PMN-MDSCs, we performed Cytoscape analysis on the proteins in the upregulated KEGG pathways of the PMN-MDSCs in B16-F10 tumour-bearing mice, and the top 10 key proteins were obtained according to the degree in the protein-protein interaction networks analysed with Cytoscape. The natural inhibitors of PMN-MDSCs were then screened from the traditional Chinese Medicine library (20000 compounds) by targeting the top 10 key proteins with molecular docking. The structures of the traditional Chinese medicines were downloaded from TCM Database@Taiwan (http://tcm. cmu.edu.tw/) [22, 23] and showed in Additional file 1. The compounds with docking score absolute values of more than 4 for all the targets were selected as candidate compounds. Finally, the weight calculation of the candidate compounds was performed according to the degree of the top 10 key proteins in Cytoscape analysis and the compound docking scores with the top 10 key proteins by using the formula proteins degree $\times$ the compound docking scores. The effects of the first five compounds on PMN- 
MDSCs were verified in vitro. All results are expressed as the mean \pm SD.

\section{In vivo experiment}

B16-F10 cells and 4 T1 cells were purchased from KeyGen Biotech (Nanjing, China). The cells were cultured with RPMI 1640 (HyClone) with 10\% foetal bovine serum (HyClone). Female C57BL/6 and BALB/C mice (6 weeks old) were purchased from the Animal Centre of the Academy of Military Medical Sciences (Beijing, China) and maintained in a temperature-controlled room with a $12 \mathrm{~h} /$ $12 \mathrm{~h}$ light/dark schedule. All animal experiments conformed to the guidelines of the Animal Ethics Committee of the Tianjin International Joint Academy of Biotechnology and Medicine. To establish the B16-F10 tumour model, we resuspended $4 \times 10^{5}$ cells in $0.1 \mathrm{~mL}$ PBS, and the suspensions were subcutaneously injected into the right lateral flank of the C57BL/6 mice. After the tumour sizes reached $120-180 \mathrm{~mm}^{3}$, the animals were randomly assigned to six groups $(n=6)$ : control, POG, $1 \mathrm{H}$-indole-3-carboxylic acid, tetrahydrofolate, okanin and 6-methoxy-2-benzoxazolinone groups. The control group only received the vehicle (5\% DMSO in 20\% hydroxypropyl beta-cyclodextrin buffer). The POG (Push bio-technology, PS00838), 1H-indole-3carboxylic acid (SIGMA-ALDRICH, 284734), tetrahydrofolate (SIGMA-ALDRICH, T3125), okanin (YUANYE, JO51 5750) and 6-methoxy-2-benzoxazolinone (SIGMA-ALDRI $\mathrm{CH}, 543551$ ) treatments were performed by intraperitoneal injection $(100 \mathrm{mg} / \mathrm{kg} /$ day) for 14 days. To evaluate the dose dependence of POG, we randomly assigned the animals when the tumour sizes reached $120-180 \mathrm{~mm}^{3}$ to three groups $(n=6)$, namely, control, POG-low and POG-high groups, which were administered vehicle (5\% DMSO in $20 \%$ hydroxypropyl beta-cyclodextrin buffer) or 100 or 200 $\mathrm{mg} / \mathrm{kg} /$ day POG intraperitoneally for 14 days. Tumour volume was measured every 3 days. Tumour volume was calculated as length $\times$ width $^{2} / 2$.

\section{Cell apoptosis assay}

To determine the cytotoxic effect of POG on PMNMDSCs, CD8 T-lymphocytes and B16-F10 cells, we sorted PMN-MDSCs and CD8 T-lymphocytes from the bone marrow and spleen of B16-F10 tumour-bearing mice, and the cells were cultured in MDSCs and T-lymphocyte media, respectively. The PMN-MDSCs, CD8 T-lymphocytes and B16-F10 cells were then divided into three groups: control, POG $(50 \mu \mathrm{M})$ and POG $(100 \mu \mathrm{M})$ groups. After $48 \mathrm{~h}$, the cells were stained with an Annexin V/PI apoptosis detection kit (KeyGen Biotech, China) and analysed by flow cytometry after the cells were incubated in the dark for $30 \mathrm{~min}$. All results are expressed as the mean $\pm \mathrm{SD}$.

\section{Cell proliferation assay}

To determine the effect of POG on PMN-MDSCs, CD8 Tlymphocytes and B16-F10 cells, we sorted PMN-MDSCs and CD8 T-lymphocytes from the bone marrow and spleen of the B16-F10 tumour-bearing mice, and the cells were cultured in MDSCs and T-lymphocyte media, respectively. PMN-MDSCs, CD8 T-lymphocytes and B16-F10 cells were stained with carboxyfluorescein succinimidyl ester (CFSE; Sigma), and PMN-MDSCs, CD8 T-lymphocytes and B16F10 cells were divided into three groups, namely, control, POG $(50 \mu \mathrm{M})$ and POG $(100 \mu \mathrm{M})$ groups. After $48 \mathrm{~h}$ POG treatment, the CFSE dilution was determined using flow cytometry analysis $[24,25]$. All the results are expressed as the mean \pm SD.

\section{Proteomic and metabolomic analysis}

To determine the effect of POG on PMN-MDSCs, we sorted PMN-MDSCs from the bone marrow of B16-F10 tumour-bearing mice, and the cells were cultured in MDSC medium. The PMN-MDSCs were then divided into two groups, namely, the control and POG $(100 \mu \mathrm{M})$ groups. After $48 \mathrm{~h}$, the cells were detected by proteomics analysis and UHPLC-QE-MS non-target metabolomics analysis. A fold change of more than 2 or 1.5 is defined as significantly different.

\section{Quantitative real-time PCR}

PMN-MDSCs were sorted from the bone marrow of the B16-F10 tumour-bearing mice, cultured in MDSC medium, and then divided into three groups, namely, the control, POG $(50 \mu \mathrm{M})$ and POG $(100 \mu \mathrm{M})$ groups. After $48 \mathrm{~h}$, the cells were harvested to examine the effect of POG on the expression of iNOS and Arg-1 in the PMN-MDSCs by using qRT-PCR. Total RNA was extracted from the PMN-MDSCs by using TRIzol reagent (Invitrogen, USA) in accordance with the manufacturer's instructions. cDNA was synthesised from the total RNA by using a PrimeScript RT reagent kit (Tiangen, China). U6 was used as an internal control. The primers used for the target genes were GAPDH 5'-AACTTTGGCATTGTGGAAGG-3' and 5'- ACACATTGGGGGTAGGAACA-3'; iNOS, 5'-AACGGAGAACGTTGGATTTG-3' and 5'-CAGCACAAGGGGTTTTCTTC-3'; and Arg1, 5'GCTGTCTTCCCAAGAGTTGGG-3' and 5'- ATGGAAGAGACCTTCAGCTAC-3'. All results are expressed as the mean \pm SD.

\section{Western blot analysis}

PMN-MDSCs were sorted from the bone marrow of the B16-F10 tumour-bearing mice, cultured in MDSC culture medium, and divided into three groups, namely, control, POG $(50 \mu \mathrm{M})$ and POG $(100 \mu \mathrm{M})$ groups. After $48 \mathrm{~h}$, the cells were harvested, and the effect of POG on the expression of iNOS and Arg-1 in the PMN-MDSCs was determined by Western blot analysis. The cells were then washed 
with PBS and lysed in ice-cold lysis buffer with protease inhibitor cocktail (Sigma) for $30 \mathrm{~min}$. The lysates were separated through SDS-PAGE and then transferred to PVDF membranes (Millipore, Bedford, MA, USA). The membranes were blocked and incubated with primary antibody Arg-1 (Affinity Bioreagents, USA) and iNOS (Affinity Bioreagents, USA). The membranes were incubated with the second antibody (Santa Cruz Biotechnology, USA). GAPDH was used as the loading control. Protein expression was detected with an enhanced chemiluminescence detection kit (Millipore, USA). Densitometric analysis was performed with ImageJ software. All results are expressed as the mean \pm SD.

\section{ARG-1, ROS and NO measurements}

PMN-MDSCs were sorted from the bone marrow of the B16-F10 tumour-bearing mice, cultured in MDSC culture medium, and divided into three groups, namely, control, POG $(50 \mu \mathrm{M})$ and POG $(100 \mu \mathrm{M})$ groups. After $48 \mathrm{~h}$, the cells were harvested. ARG1 activity, ROS and $\mathrm{NO}$ were detected by using an ARG1 activity assay kit (Abcam), DCFDA (Invitrogen) and a Griess reagent system (Promega) in accordance with the manufacturer's instructions. All results are expressed as the mean \pm SD.

\section{T-lymphocyte proliferation assay}

T-lymphocytes sorted from the spleens of the B16-F10 tumour-bearing mice were cultured in T-lymphocyte medium and stained with CFSE (Sigma). After the cells were co-cultured with PMN-MDSCs or M-MDSCs for $48 \mathrm{~h}$, the cells were stained for surface markers with CD8 antibody (clone 53-6.7, eBioscience). The CFSE dilution in CD8 Tlymphocytes was determined through flow cytometry analysis $[24,25]$. All results are expressed as the mean \pm SD.

\section{IFN- $\gamma$ production assays}

T-lymphocytes sorted from mouse spleens were cultured in T-lymphocyte medium with or without POG. After 48 $h$, supernatant IFN- $\gamma$ levels were quantified by ELISA (eBioscience) in accordance with the manufacturer's instructions. All the results are expressed as the mean \pm SD.

\section{Effect of POG combined with PD-1 inhibitor in vivo}

The B16-F10 tumour model was established by using the method described above. To establish the 4 T1 tumour model, we injected the resuspended $4 \times 10^{5} 4 \mathrm{~T} 1$ cells in $0.1 \mathrm{~mL}$ PBS into the fourth pair of the mammary fat pad of $\mathrm{BALB} / \mathrm{C}$ mice. When the tumour volumes of B16-F10 and 4 T1 tumour-bearing mice reached $120-180 \mathrm{~mm}^{3}$, the mice were randomly distributed into the following groups $(n=$ 6): control, POG, anti-PD-1 (Bio X Cell RPM1-14, rat IgG2a) and a combination of POG and anti-PD-1 groups. The control group was treated with the vehicle alone (5\% DMSO in 20\% hydroxypropyl beta-cyclodextrin buffer).
The POG group was administered intraperitoneally daily at 100 and $200 \mathrm{mg} / \mathrm{kg}$ for 14 days. Anti-PD-1 antibody (clone RMP1-14, Bio X Cell) or isotype control antibody (clone 2A3, Rat IgG2a, Bio X Cell) was intraperitoneally given on days 11, 14, 17, 20 and 23 (200 $\mu \mathrm{g}$ /injection). Tumour volume was measured every 3 days. Tumour volume was calculated as length $\times$ width $^{2} / 2$.

\section{Statistical analysis}

All statistical analyses were performed with GraphPad Prism7 software for Windows. Statistically significant differences were calculated by using Student's t-test. Overall survival analysis was performed by using the Kaplan-Meier method with the log-rank test, and a $p$ value of $<0.05$ was considered statistically significant.

\section{Results}

More PMN-MDSCs accumulated in B16-F10 tumourbearing mice than in naive mice

When the tumour volume reached $1000 \mathrm{~mm}^{3}$, the naive mice and B16-F10 tumour-bearing mice were sacrificed, and the proportion of MDSCs in the spleen and bone marrow samples was measured. The results showed that the proportion of MDSCs in the spleen and bone marrow samples of the B16-F10 tumour-bearing mice considerably increased relative to the proportion in the naive mice. The CD11b ${ }^{+}$Ly- $6 G^{+}$Ly- $6 C^{\text {low }}$ PMN-MDSC population in the bone marrow and spleen samples of the B16-F10 tumourbearing mice increased more significantly than the

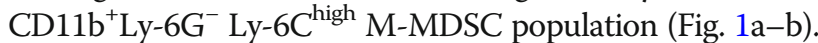
We sorted naive PMN-MDSCs, B16-F10 tumour-bearing PMN-MDSCs, naive M-MDSCs and B16-F10 tumourbearing PMN-MDSCs and then co-cultured these cells with CD8 T-lymphocytes at 4:1, 2:1, 1:1 and 1:2. The results of T-lymphocyte proliferation experiments showed that the ability of PMN-MDSCs to inhibit CD8 T-lymphocyte proliferation is stronger than that of M-MDSCs in B16-F10 tumour-bearing mice (Fig. 1c-d).

\section{Differentially expressed genes of PMN-MDSCs in tumour- bearing mice are mainly enriched in proliferation and metabolism-related pathways}

The PMN-MDSCs sorted from the bone marrow of the naive and B16-F10 tumour-bearing mice were collected for proteomic analysis and analysed by the DAVID database. The results of GO analysis showed that the upregulated genes of PMN-MDSCs in tumour-bearing mice were enriched in the function of proliferation and metabolism compared with PMN-MDSCs in naive mice. The enhanced functions included cell cycle, cell division, metabolic process-related biological processes (Fig. 2a) and oxidoreductase activity, NADH dehydrogenase activity and electron carrier activity-related molecule function (Fig. 2c). The 
A

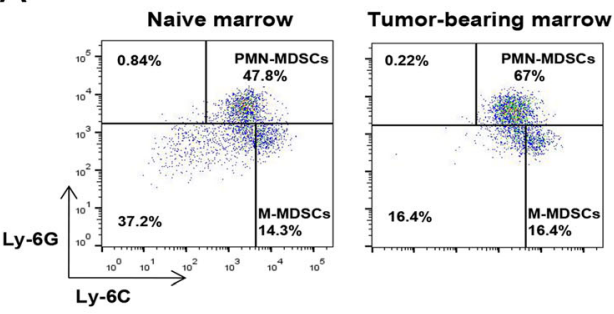

B

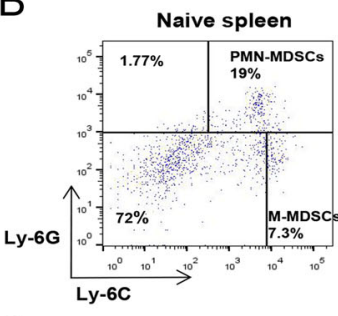

Tumor-bearing spleen
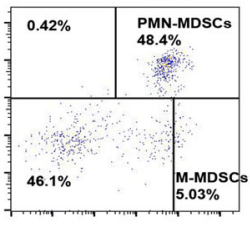

- Naive marrow

Tumor-bearing marrow

M-MDSCs
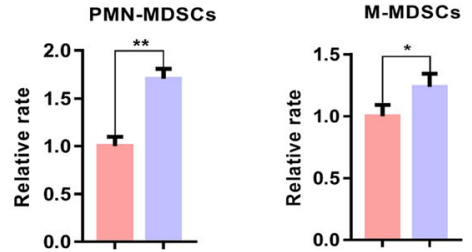

Naive spleen

Tumor-bearing spleen M-MDSCs
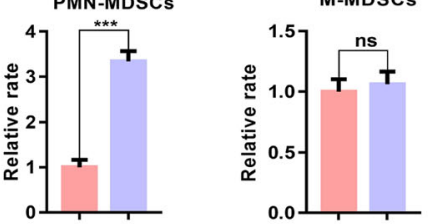

C

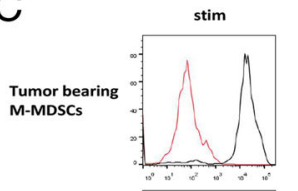

M-MDSCS : CD8T 2:1
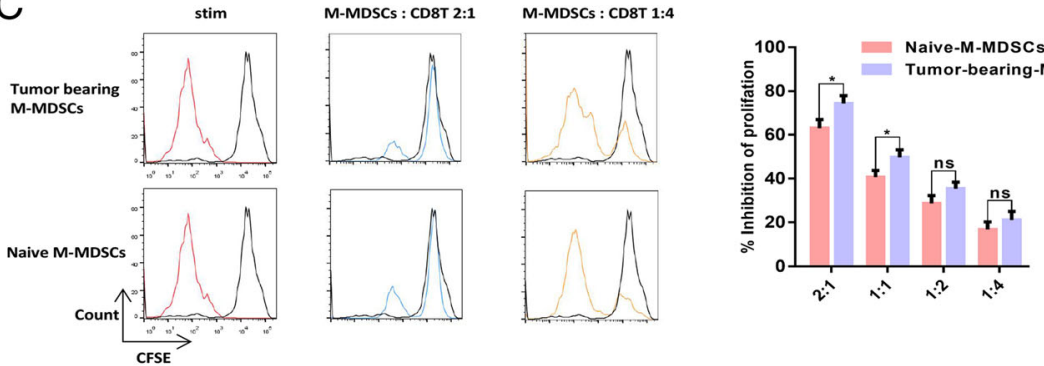

D

tim
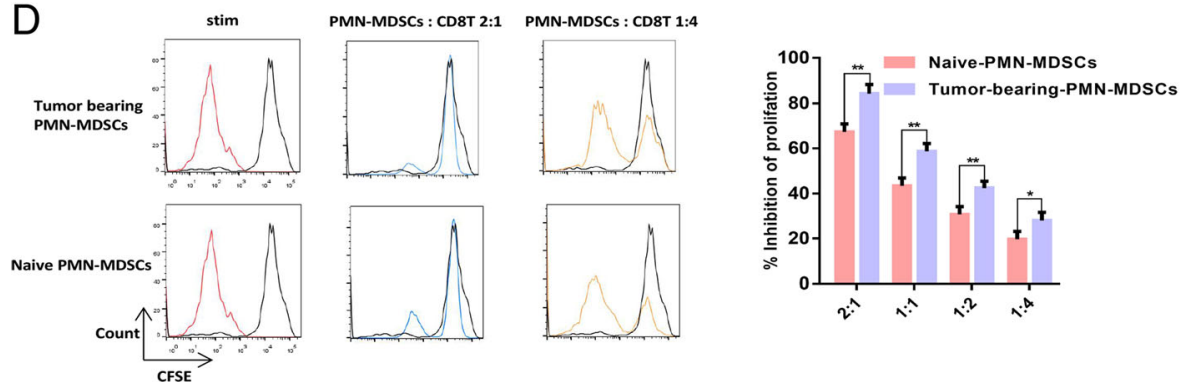

Fig. 1 PMN-MDSCs accumulated in B16-F10 tumour-bearing mice in contrast to those in naive mice. a Dotplots of live CD11 b cells in the bone marrow of naive or B16-F10 tumour-bearing mice (left panels) and relative proportions of PMN-MDSCs (CD11 b ${ }^{+}$Ly6G ${ }^{+}$Ly6 $6 C^{\text {low }}$ ) and M-MDSCs $\left(\mathrm{CD} 11 \mathrm{~b}^{+} \mathrm{Ly}_{6 \mathrm{G}^{-}} \mathrm{Ly}_{6} \mathrm{C}^{\text {high)}}\right.$ ) in the bone marrow of naive and B16-F10 tumour-bearing mice (right charts). $\mathbf{b}$ Dotplots of live CD $11 \mathrm{~b}^{+}$cells in the spleens of naive mice or B16-F10 tumour-bearing mice (left panels), and relative proportions of PMN-MDSCs (CD11 b $\left.{ }^{+} \mathrm{Ly}_{6 G^{+}} \mathrm{Ly}_{6} \mathrm{C}^{\mathrm{low}}\right)$ and MMDSCs (CD1 1 b ${ }^{+}{\text {Ly } 6 G^{-} \text {Ly6 }}^{\text {high }}$ ) in the spleens of naive and B16-F10 tumour-bearing mice (right charts). c-d Dose-dependent suppression of CD8 T-lymphocyte proliferation by sorted bone marrow M-MDSCs and PMN-MDSCs. Representative CFSE histograms are shown (unstimulated CFSElabelled T-lymphocytes in black). The pooled data from three independent experiments are shown. All data are represented as the mean \pm SD. ${ }^{*} p<0.05,{ }^{* *} p<0.01,{ }^{* * *} p<0.001,{ }^{* * *} p<0.0001$

upregulated genes associated with the cell cycle, cell division and metabolic process in the B16-F10 tumour-bearing PMN-MDSCs are shown in Fig. 2b. The upregulated genes associated with oxidoreductase, $\mathrm{NADH}$ dehydrogenase and electron carrier activities in the B16-F10 tumour-bearing PMN-MDSCs are shown in Fig. 2d. The KEGG analysis showed that the upregulated genes of PMN-MDSCs in B16-F10 tumour-bearing mice were enriched in cell proliferation and metabolic pathways, such as the metabolic pathways, tricarboxylic acid cycle (TCA cycle) and DNA replication (Fig. 2e). Furthermore, we analysed the proteinprotein interaction of the upregulated differential genes of B16-F10 tumour-bearing PMN-MDSCs by using the STRING database. The results showed that the upregulated genes were mainly related to cell metabolism (Fig. 2f). 

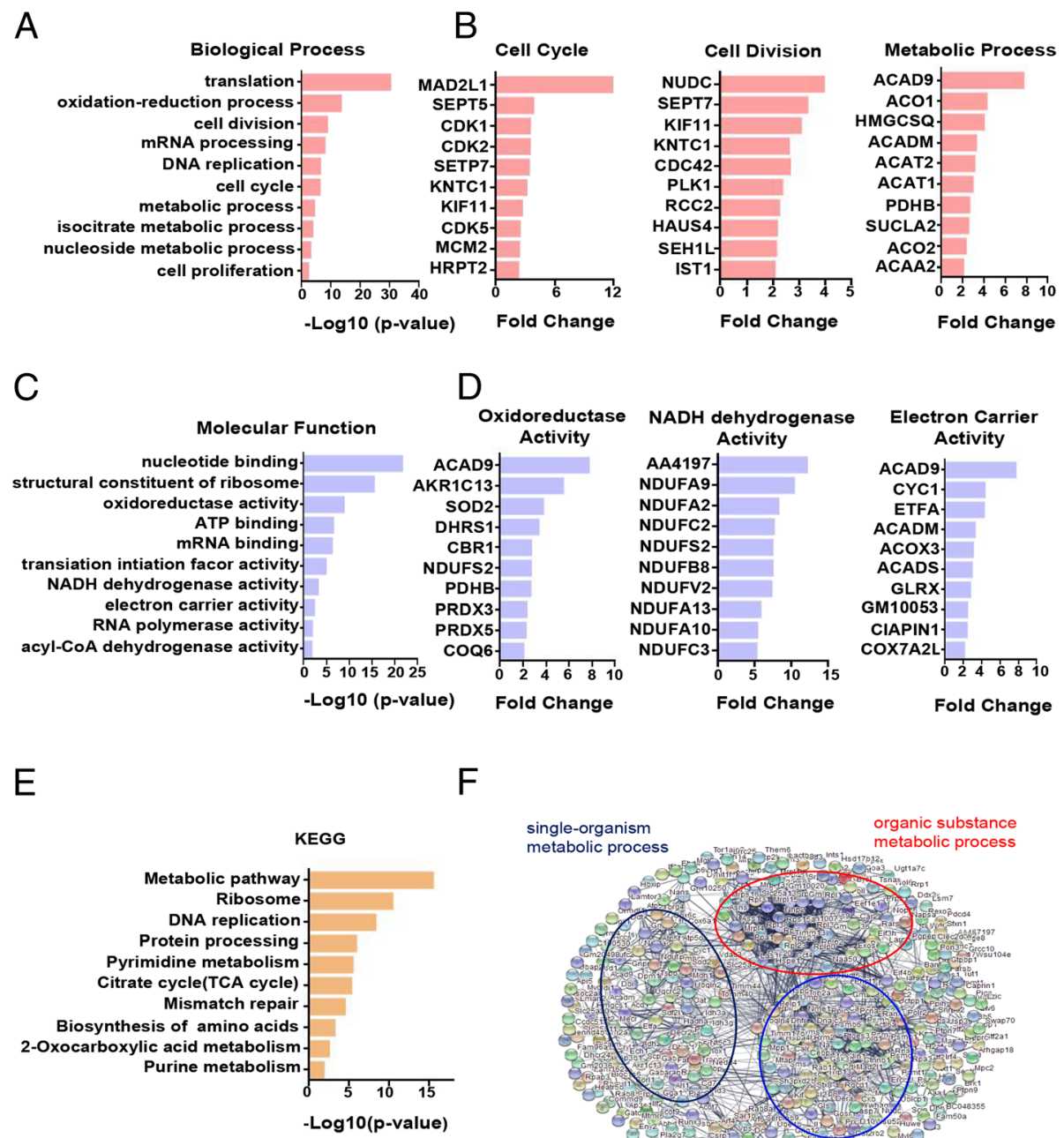

F

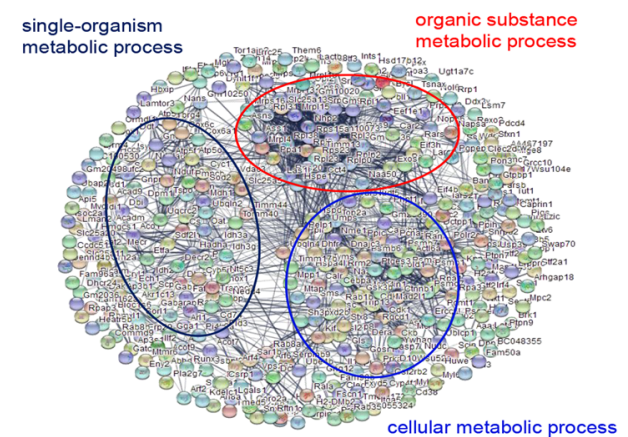

Fig. 2 Differentially expressed genes of PMN-MDSCs in tumour-bearing mice are mainly enriched in proliferation and metabolism-related pathways. a Statistical analysis of upregulated biological processes of B16-F10 tumour-bearing PMN-MDSCs. b The upregulated genes associated with the cell cycle, cell division and metabolic process of B16-F10 tumour-bearing PMN-MDSCs. c Statistical analysis of the upregulated molecular function of B16-F10 tumour-bearing PMN-MDSCs. d The upregulated genes associated with oxidoreductase, NADH dehydrogenase and electron carrier activities. e KEGG analysis of the upregulated genes of B16-F10 tumour-bearing PMN-MDSCs (f). The protein-protein interaction networks of upregulated proteins of B16-F10 tumour-bearing PMN-MDSCs. Significantly changed proteins are correlated with cell metabolism

POG, a natural inhibitor of PMN-MDSCs, was screened using molecular docking and weight calculation of

\section{docking scores}

Based on the results of proteomic analysis, we found that the major enhancement pathways of the PMN-MDSCs in B16-F10 tumour-bearing mice were related to proliferation and metabolism. We then screen the key proteins in these pathways and the inhibitors that repressed these pathways by targeting the key proteins. We performed Cytoscape analysis of the proteins in the upregulated KEGG pathways and then ranked the top key 10 proteins in these pathways in accordance with the degree level in the Cytoscape analysis (Fig. 3a). We then screened natural inhibitors of MDSCs from the traditional Chinese Medicine library by targeting the top 10 key proteins with molecular docking. The compounds with a docking score absolute value with all 10 key proteins of more than 4 were selected as candidate inhibitors (Fig. $3 \mathrm{~b}-\mathrm{c}$ ). The structure of 10 candidate inhibitors could be found in the Appendix. We then performed weight calculations of candidate inhibitors to sort the candidate inhibitors (Fig. 3d). Furthermore, we verified the inhibitory activities of the top 5 candidate inhibitors, namely, POG, $1 \mathrm{H}$-indole-3-carboxylic acid [26], tetrahydrofolate [27], okanin [28] and 6-methoxy-2-benzoxazolinone [29], on PMN-MDSCs in vitro and in vivo. In vitro, bone marrow cells from the B16-F10 tumour-bearing mice were treated with the vehicle control and $100 \mu \mathrm{M}$ of the top 5 compounds. After $48 \mathrm{~h}$, we evaluated the percentages of 


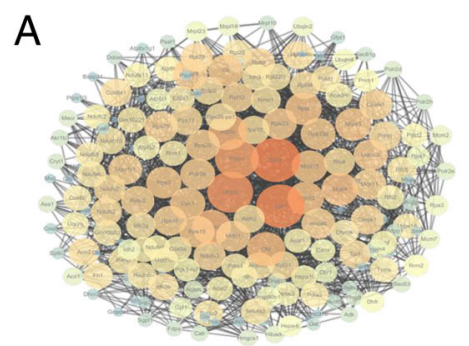

\begin{tabular}{lclc}
\hline Gene & Degree & Gene & Degree \\
\hline Eprs & 66 & Hadha & 46 \\
Gart & 64 & Dld & 45 \\
Umps & 59 & Mrpl4 & 42 \\
Paics & 55 & Rpl8 & 41 \\
Atp5o & 47 & Mrpl13 & 41 \\
\hline
\end{tabular}

B

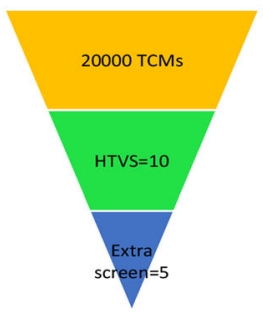

E

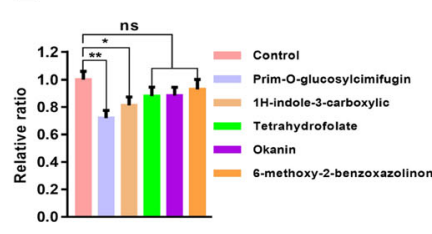

C

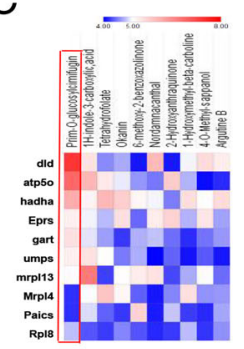

$\mathrm{F}$

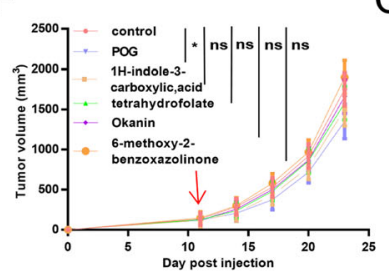

D

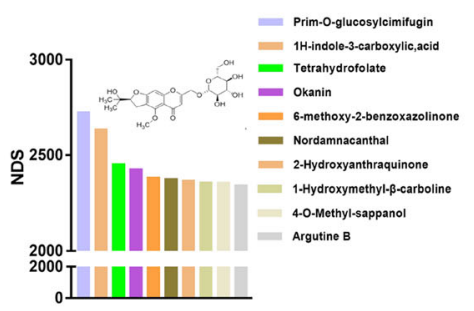

G

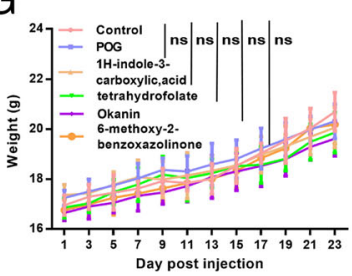

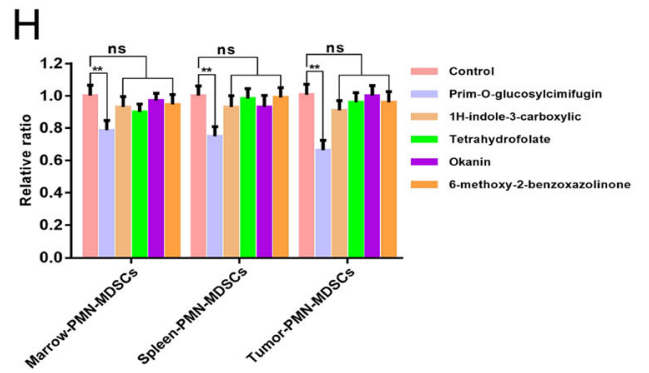

I

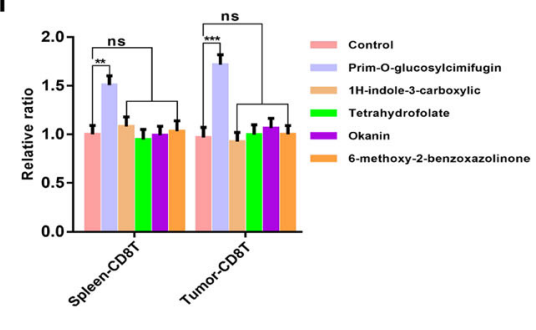

Fig. 3 POG, as a natural inhibitor of PMN-MDSCs, is screened by molecular docking and weight calculation of docking scores. a Cytoscape analysis of the proteins in the upregulated KEGG pathway of B16-F10 tumour-bearing PMN-MDSCs and the top 10 key proteins of upregulation proteins of B16-F10 tumour-bearing PMN-MDSCs obtained according to the Cytoscape analysis degree. $\mathbf{b}$ Screening result of PMN-MDSC inhibitors from the traditional Chinese Medicine library with the top 10 key proteins as targets by molecular docking and weight calculation of docking score. c The 10 compounds from the traditional Chinese Medicine library, which binds well with 10 key proteins, and the absolute value of docking scores are more than 4 with all 10 proteins. $\mathbf{d}$ Weight calculation of the 10 compounds from the traditional Chinese Medicine library. e Inhibitory effect of the top 5 compounds on PMN-MDSCs (CD11 b+ Ly6G ${ }^{+}$Ly6Clow) in vitro. $\mathbf{f}$ The tumour growth curves of B16-F10 tumourbearing mice after the top 5 compound treatments $(n=6)$. $\mathbf{g}$ Body weight of B16-F10 tumour-bearing mice after the top 5 compound treatments $(n=6)$. $\mathbf{h}$ Relative proportion of PMN-MDSCs $\left(C D 11 b^{+}{\text {Ly } 6 G^{+}}^{2}\right.$ Ly6 $\left.C^{\text {low }}\right)$ in bone marrow, spleen and CD45 $5^{+}$cells from tumours of control and top 5 compound-treated B16-F10 tumour-bearing mice $(n=6)$. i Relative proportion of CD8 T-lymphocytes $\left(C D 3^{+} \mathrm{CD} 8^{+}\right)$in spleens and $\mathrm{CD}_{4} 5^{+}$cells from tumours of control and top 5 compound-treated B16-F10 tumour-bearing mice $(n=6)$. The pooled data from three independent experiments are shown. All data are represented as the mean $\pm \mathrm{SD} .{ }^{*} p<0.05,{ }^{* *} p<0.01,{ }^{* * *} p<0.001,{ }^{* * *} p<0.0001$

PMN-MDSCs in bone marrow cells by flow cytometry and found that POG exhibited the best inhibitory effect on PMN-MDSCs (Fig. 3e). In vivo, a B16-F10 subcutaneous tumour model in C57BL6 mice was established for the evaluation of the antitumour effects of the top five compounds. We found that POG exhibited the best antitumour effect at a dose of $100 \mathrm{mg} / \mathrm{kg}$ and reduced the proportion of PMN-MDSCs in the bone marrow, spleen and $\mathrm{CD} 5^{+}$cells in tumours (Fig. 3f-h). POG also increased the number of CD8 T-lymphocytes in the spleens and $\mathrm{CD} 45^{+}$cells in tumour samples at a dose of $100 \mathrm{mg} / \mathrm{kg}$. (Fig. 3i). 

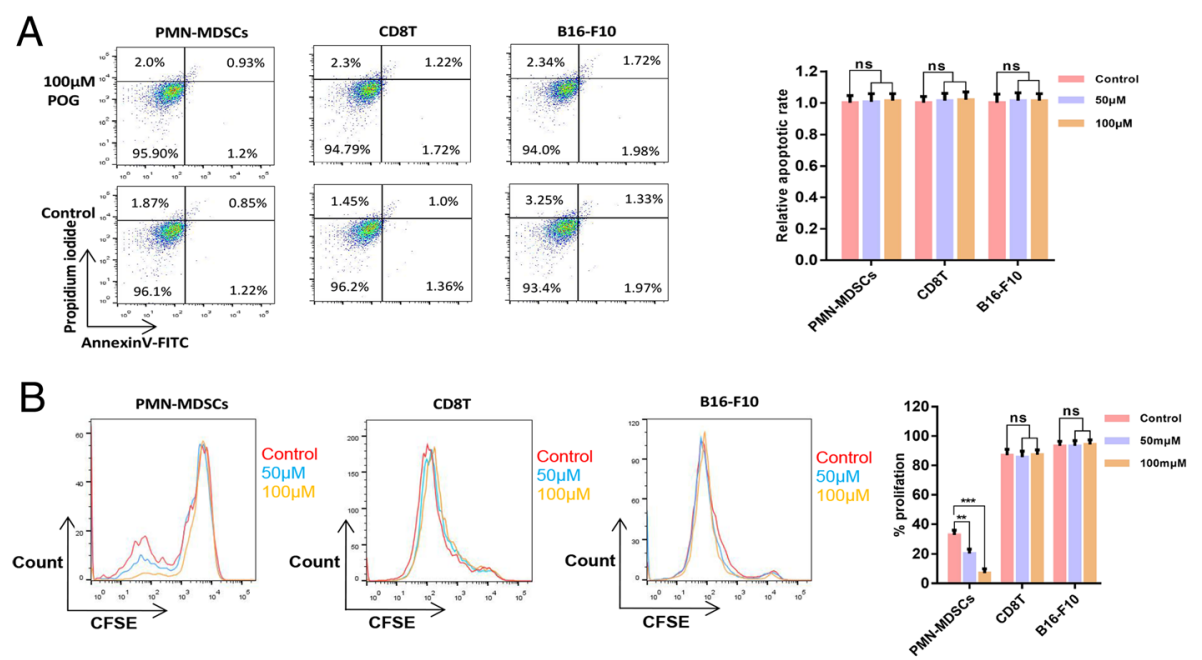

C

D

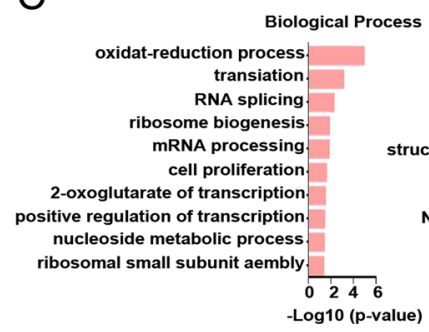

E
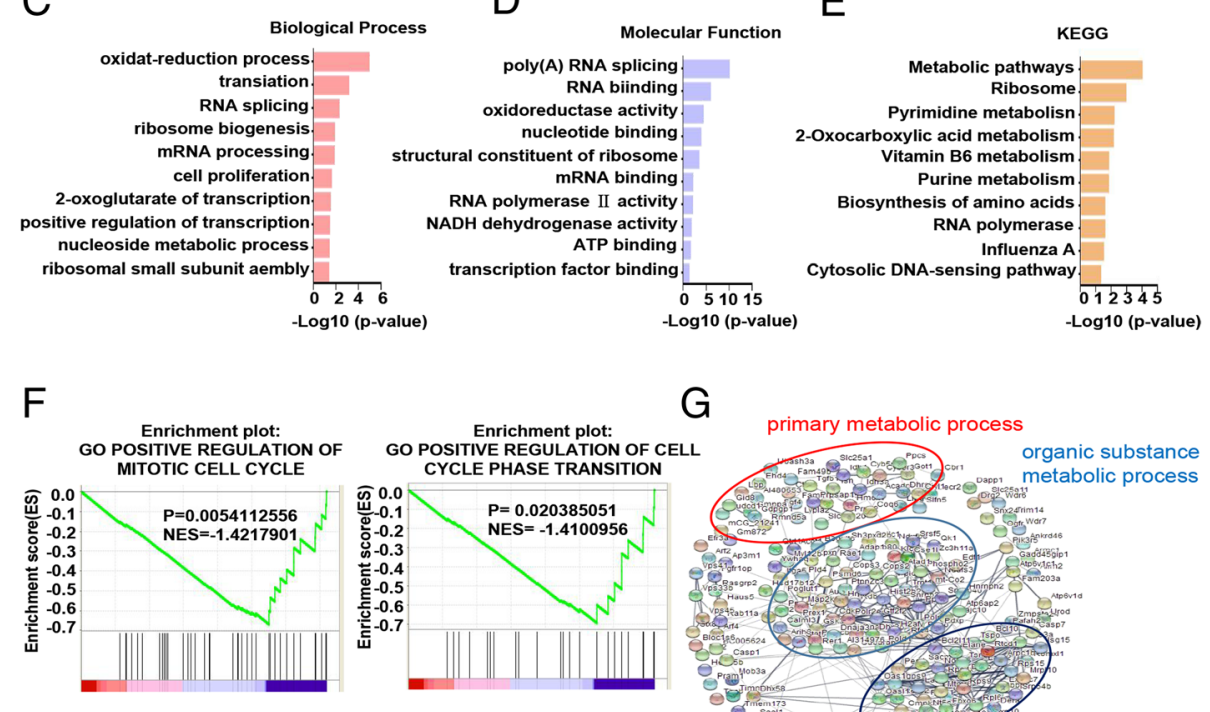

$\mathrm{G}$

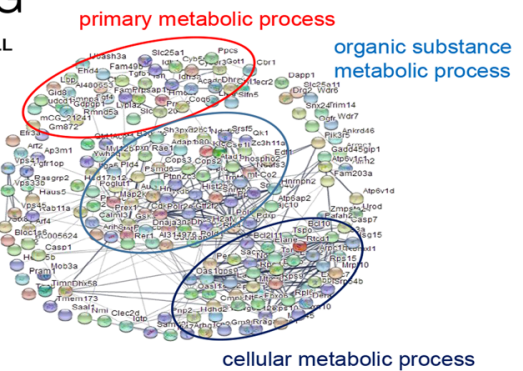

Fig. 4 POG inhibits the proliferation and metabolism of PMN-MDSCs in vitro. a The cytotoxic effect of POG on PMN-MDSCs, CD8 T-lymphocytes and B16-F10 cells. $\mathbf{b}$ Effect of POG on the proliferation of PMN-MDSCs, CD8 T-lymphocytes and B16-F10 cells. c Statistical analysis of downregulated biological processes of B16-F10 tumour-bearing PMN-MDSCs after POG treatment. $\mathbf{d}$ Statistical analysis of the downregulated molecular function of B16-F10 tumour-bearing PMN-MDSCs after POG treatment. e KEGG analysis of the downregulated genes of B16-F10 tumour-bearing PMN-MDSCs after POG treatment. $\mathbf{f}$ GSEA analysis of the downregulated genes of B16-F10 tumour-bearing PMN-MDSCs after POG treatment. $\mathbf{g}$ The protein-protein interaction networks of downregulated proteins of B16-F10 tumour-bearing PMN-MDSCS after POG treatment. The pooled data from three independent experiments are shown. All data are represented as the mean $\pm \mathrm{SD}$. ${ }^{*} p<0.05$, ${ }^{* *} p<0.01$, ${ }^{* * *} p<0.001,{ }^{* * * *} p<0.0001$

\section{POG inhibits the proliferation and metabolism of PMN- MDSCs in vitro}

To verify the inhibitory effect of POG on PMN-MDSCs, we evaluated the effects of POG on apoptosis and proliferation of PMN-MDSCs, CD8 T-lymphocytes and B16-F10 cells. The results showed that POG exhibited no cytotoxic effect on PMN-MDSCs, CD8 T-lymphocytes and B16-F10 cells. However, POG could specifically inhibit the proliferation of PMN-MDSCs (Fig. 4a-b). To detect the key cellular signalling pathways affected by POG, we performed proteomics and metabolomics analysis. Proteomic profile changes in the POG-treated PMN-MDSCs were analysed. Consistent with the results of the upregulated proteins of B16-F10 tumour-bearing PMN-MDSCs, the results of GO analysis showed that the functions of cell proliferation, oxidation-reduction process, nucleoside metabolic process-related biological processes (Fig. 4c), $\mathrm{NADH}$ dehydrogenase activity, oxidoreductase activity 
and ATP binding-related molecule function of the PMNMDSCs were downregulated after POG treatment (Fig. 4d). KEGG analysis results showed that after POG treatment, the RNA polymerase, biosynthesis of amino acids and metabolic pathways of the PMN-MDSCs were downregulated (Fig. 4e). GSEA analysis also revealed that POG mainly inhibits the cell cycle of PMN-MDSCs (Fig. 4f). Furthermore, we analysed the protein interaction in the downregulated genes after POG treatment with the STRING database. The results indicated that the downregulated genes after POG treatment were mainly related to cell metabolism (Fig. 4g). These findings showed that POG could inhibit the proliferation and metabolism of PMN-MDSCs. The metabolomics results showed that POG mainly inhibited arginine and proline metabolism and the citrate cycle in the PMN-MDSCs. Through
A

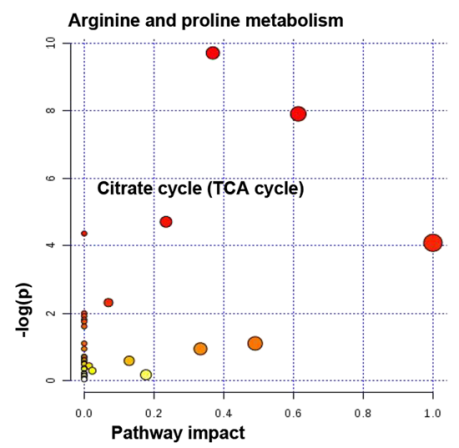

C

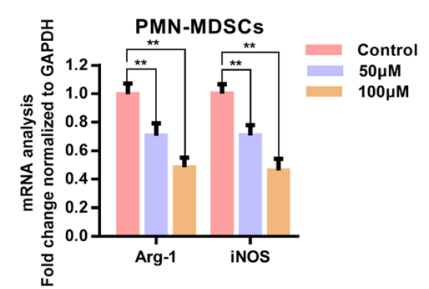

B

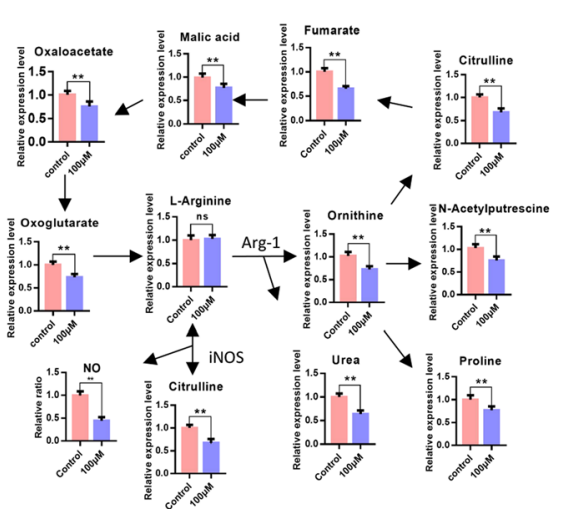

$\mathrm{D}$
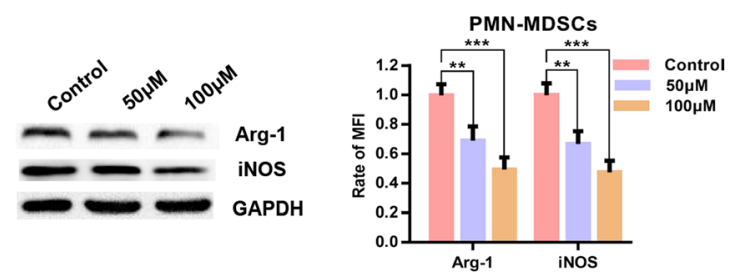

$\mathrm{E}$
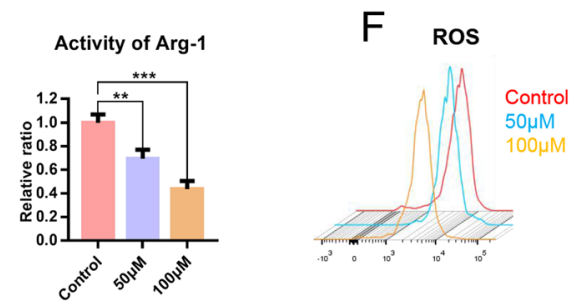

$\mathrm{H}$
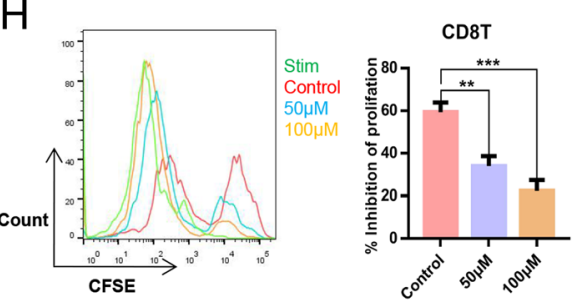
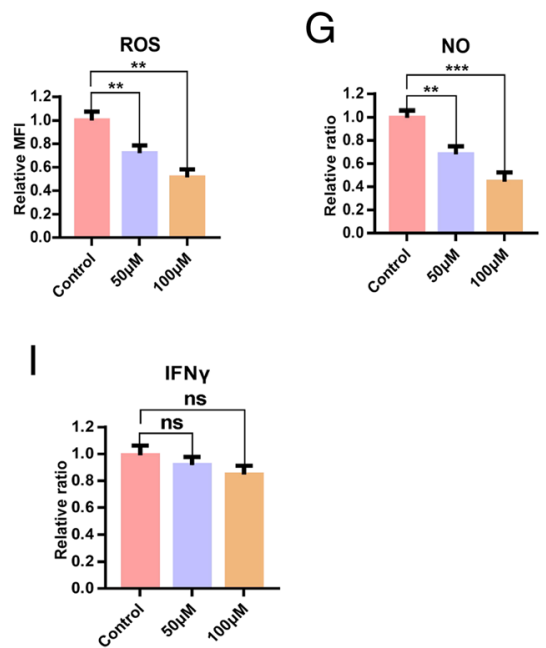

Fig. 5 POG inhibits the immunosuppressive capacity of PMN-MDSCs without affecting the function of T-lymphocytes in vitro. $\mathbf{a}$-b Results of the metabolomics analysis of B16-F10 tumour-bearing PMN-MDSCs after POG treatment. c qRT-PCR detection of the effect of POG on iNOS and Arg-1 expression levels of PMN-MDSCs. $\mathbf{d}$ Western blot analysis of the effect of POG on iNOS and Arg-1 expression levels in PMN-MDSCs. e-g Effect of POG on ARG1 activity (E), ROS (F) and NO (g) production of the PMN-MDSCs. $\mathbf{h}$ Effect of POG on the ability of PMN-MDSCs to inhibit the proliferation of CD8 T-lymphocytes. i Effect of POG on the IFN- $y$ content in CD8 T-lymphocytes. The pooled data from three independent experiments are shown. All data are represented as the mean \pm SD. ${ }^{*} p<0.05,{ }^{* *} p<0.01,{ }^{* * *} p<0.001,{ }^{* * *} p<0.0001$ 
pathway analysis, we found that after POG treatment, the metabolic pathways of arginine into ornithine and citrulline regulated by ARG-1 and iNOS were downregulated, and the metabolism of citrulline and ornithine further affected the TCA cycle (Fig. 5a-b).

\section{POG inhibits the immunosuppressive capacity of PMN- MDSCs without affecting the function of CD8 T- \\ lymphocytes in vitro}

To verify the inhibitory effect of POG on arginine metabolism in B16-F10 tumour-bearing PMN-MDSCs, we used qRT-PCR and Western blot analysis to examine the effect of POG on the expression of iNOS and Arg-1 in PMN-MDSCs. The results showed that POG decreased the expression of Arg-1 and iNOS in PMN-MDSCs (Fig. 5c-d). We then examined the ARG1 activity, ROS and NO levels of the PMNMDSCs after POG treatment. The findings revealed that POG inhibited ARG1 activity, the production of ROS and the production of NO in PMN-MDSCs (Fig. $5 \mathrm{e}-\mathrm{g})$. To evaluate the effect of POG on the immunosuppressive capacity of PMN-MDSCs, we co-cultured the control and POG-treated PMN-MDSCs with CD8 T-lymphocytes at 1:1 for $48 \mathrm{~h}$ to detect the proliferation of CD8 T-lymphocytes. The results indicated that POG inhibited the inhibitory activity of the PMNMDSCs on T-lymphocyte proliferation (Fig. 5h). To evaluate the effect of POG on CD8 T-lymphocyte function, we co-cultured CD8 T-lymphocytes with POG in T-lymphocyte medium for $48 \mathrm{~h}$ to examine the production of IFN- $\gamma$ in T-lymphocytes. The results showed that POG did not influence the production of IFN- $\gamma$ in CD8 T-lymphocytes (Fig. 5i).

\section{POG exerts a dose-dependent antitumour effect and improves the immunosuppressive microenvironment of tumours}

We established the B16-F10 subcutaneous tumour model in C57BL6 mice to evaluate the dose-dependent effect of POG on B16-F10 primary tumour growth and the tumour immunosuppressive microenvironment. The results showed that POG resulted in significant inhibition of tumour growth dose-dependently, and 200 $\mathrm{mg} / \mathrm{kg}$ exerted no significant effect on the body weight of mice (Fig. 6a-c). To investigate the dose-dependent effect of POG on the immunosuppressive microenvironment, the proportion of PMN-MDSCs and CD8 Tlymphocytes in the spleens, bone marrow and tumours of mice in the control group and the POG-treated group was compared. The results showed that the proportion of PMN-MDSCs in bone marrow, spleen and $\mathrm{CD} 45^{+}$cells from tumours was reduced, and the proportions of CD8 T-lymphocytes in spleens and CD45 cells from tumours were increased dose-dependently after treatment with POG (Fig. 6d-e). To investigate the effect of POG on the immunosuppressive ability of PMN-MDSCs, we co-cultured PMN-MDSCs sorted from the bone marrow and tumours of the control and POG-treated B16-F10 tumour-bearing mice with CD8 T-lymphocytes at 1:1. CD8 T-lymphocyte proliferation was examined after $48 \mathrm{~h}$. The results showed that the immunosuppressive ability of PMN-MDSCs from the bone marrow and tumours in the POG-treated group considerably decreased relative to that of the control group in a dose-dependent manner (Fig. $6 \mathrm{f}-\mathrm{g}$ ). To assess the effect of POG on CD8 T-lymphocyte proliferation and function, we sorted the CD8 T-lymphocytes from the spleens of the control and POG-treated B16F10 tumour-bearing mice. After $48 \mathrm{~h}$, we examined the proliferation and IFN- $\gamma$ production ability of spleen CD8 T-lymphocytes. The results showed that POG did not affect the proliferation and IFN- $\gamma$ production ability of the spleen CD8 T-lymphocytes (Fig. 6h-i). These results showed that POG selectively inhibited the proliferation and immunosuppression of PMN-MDSCs and improved the immunosuppressive microenvironment of B16-F10 tumour-bearing mice, thereby inhibiting tumour growth in vivo in a dose-dependent manner.

\section{POG enhances the antitumour effect of PD-1 inhibitor in B16-F10 and 4 T1 mouse tumour models}

Given that POG reduced PMN-MDSCs in the bone marrow and tumours and increased CD8 T-lymphocytes in the spleens and tumours of the B16-F10 tumourbearing mice, we hypothesised that POG enhances the antitumour effect of the PD-1 inhibitor. We established mouse B16-F10 subcutaneous and 4T1 in situ tumour models. The results showed that the combination of POG and PD-1 mAb group showed better antitumour effects than did the POG and PD-1 mAb groups. The combination index [30] of POG $(100 \mathrm{mg} / \mathrm{kg})$ and POG $(200 \mathrm{mg} / \mathrm{kg}$ ) with PD-1 mAb was 1.27 and 1.32 in the B16-F10 tumour model and 1.23 and 1.21 in the 4 T1 tumour model, respectively (Fig. $7 \mathrm{a}-\mathrm{d}$ ). The combination group also showed the best ability to prolong survival time of B16-F10 and 4 T1 tumour-bearing mice compared with the other groups (Fig. 7e-h). These results indicated that POG and PD-1 inhibitors exhibited synergistic antitumour effects.

\section{Discussion}

MDSCs comprise a highly immunosuppressive population of tumour-infiltrating immature myeloid cells that contribute to tumour immune escape by inhibiting cytotoxic $\mathrm{T}$-lymphocyte proliferation and driving $\mathrm{T}$ regulatory cell induction [31,32]. MDSCs penetrate the entire tumour and are correlated with tumour size and 
A

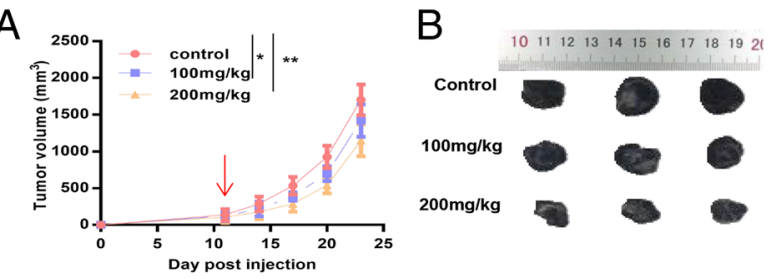

D
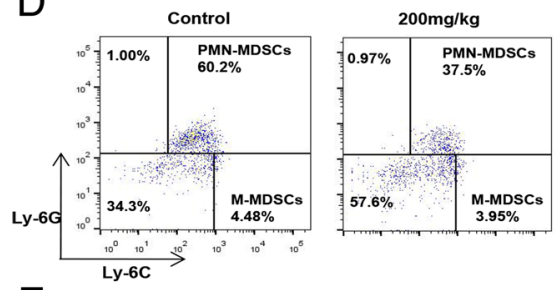

E
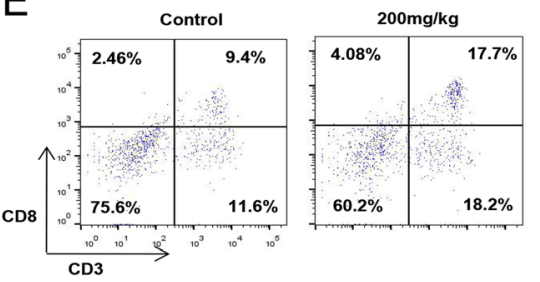

F

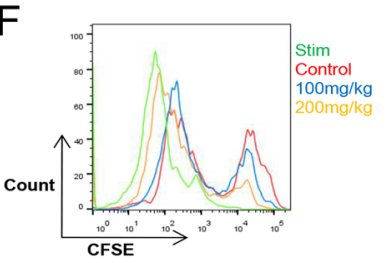

$\mathrm{H}$

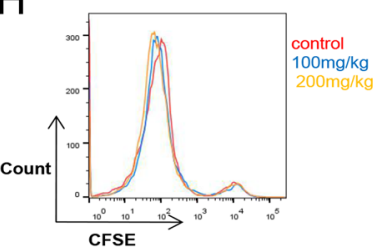

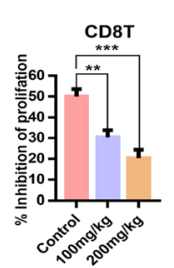

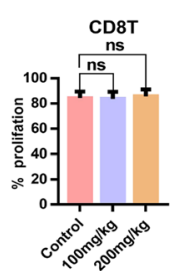

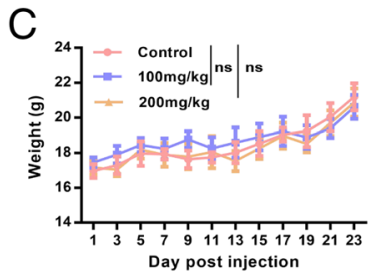
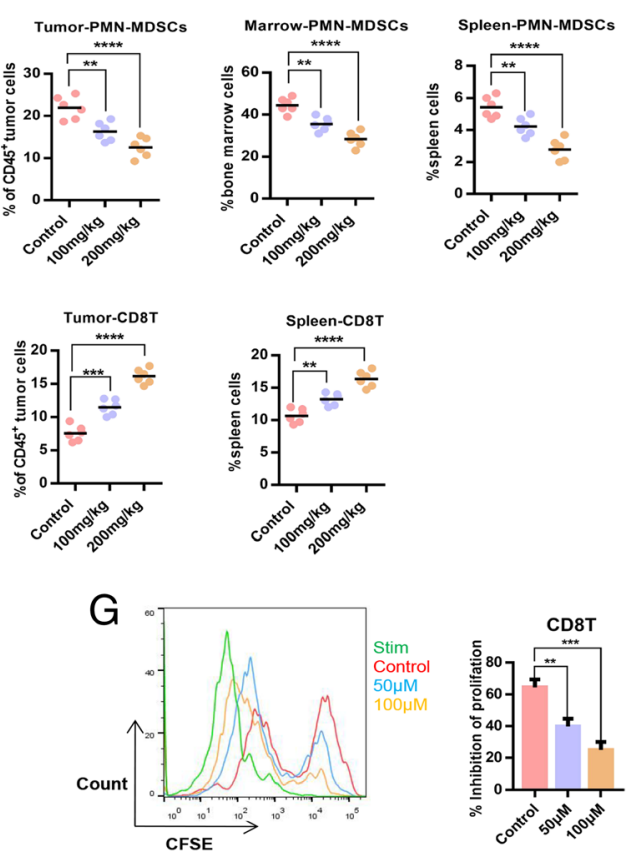

I

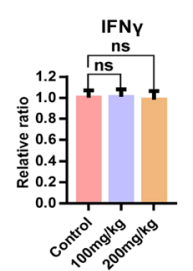

Fig. 6 POG exerts a dose-dependent antitumour effect and improves the immunosuppressive microenvironment of tumours. a Tumour growth curves of B16-F10 tumour-bearing mice after POG treatment $(n=6)$. b Representative tumour images of control and POG-treated B16-F10 tumour-bearing mice $(n=6)$. c Body weight of B16-F10 tumour-bearing mice after POG treatment $(n=6)$. $\mathbf{d}$ Dotplots of live, CD45 CD11 ${ }^{+}$cells in the tumours of control and POG-treated B16-F10 tumour-bearing mice (left panels) and proportion of PMN-MDSCS (CD11 ${ }^{+} L y 6 G^{+} L y 6 C^{\text {low }}$ ) in bone marrow, spleen and CD45 ${ }^{+}$cells from tumours of control and POG-treated B16-F10 tumour-bearing mice $(n=6)$ (right charts). e Dotplots of live, CD45 cells in the tumours of control and POG-treated B16-F10 tumour-bearing mice (left panels) and proportion of CD8 T-lymphocytes $\left(\mathrm{CD}^{+} \mathrm{CD}^{+}\right)$in spleens and $\mathrm{CD} 45^{+}$cells from tumours of control and POG-treated B16-F10 tumour-bearing mice $(n=6)($ right charts). $\mathbf{f}-\mathbf{g}$ Ability of PMN-MDSCs sorted from bone marrow (f) or tumours (g) of control and POG-treated B16-F10 tumour-bearing mice to inhibit CD8 Tlymphocyte proliferation $(n=6)$. $\mathbf{h}$ Proliferation of CD8 T-lymphocytes sorted from the spleens of control and POG-treated B16-F10 tumourbearing mice $(n=6)$. i IFN- $y$ content of CD8 T-lymphocytes sorted from the spleens of control and POG-treated B16-F10 tumour-bearing mice $(n=6)$. The pooled data from three independent experiments are shown. All data are represented as the mean $\pm \mathrm{SD}$. ${ }^{*} p<0.05,{ }^{*} p<0.01$, ${ }^{* * *} p<0.001,{ }^{* * * *} p<0.0001$

malignancy. Therefore, targeting MDSCs is an important therapeutic strategy for tumour immunotherapy.

In the present study, we found that PMN-MDSCs heavily accumulated in the spleens and bone marrow of B16F10 tumour-bearing mice, and the proliferation, metabolism and immunosuppression of B16-F10 tumour-bearing
PMN-MDSCs increased. We selected the top 10 key proteins, namely, Eprs, Gart, Umps, Paics, Atp5o, Hadha, Dld, Mrpl4, Rpl8 and Mrpl13, in the upregulated KEGG pathways of B16-F10 tumour-bearing PMN-MDSCs as targets to screen the natural inhibitors of PMN-MDSCs from the traditional Chinese Medicine library (20000 compounds). 

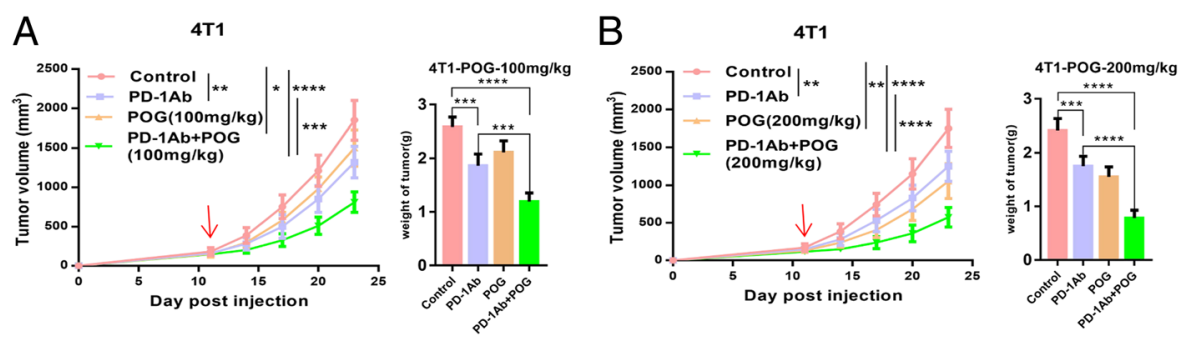

C

$\mathrm{D}$
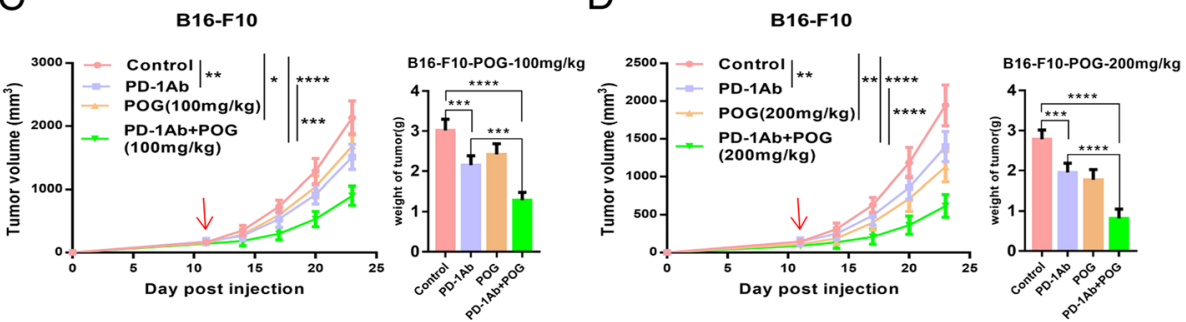

E

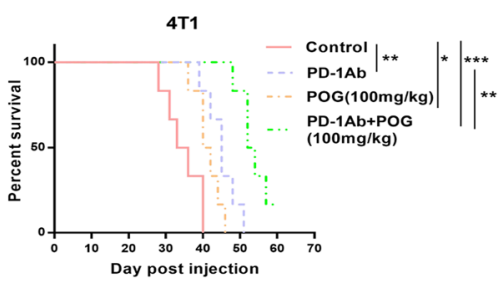

$\mathrm{F}$

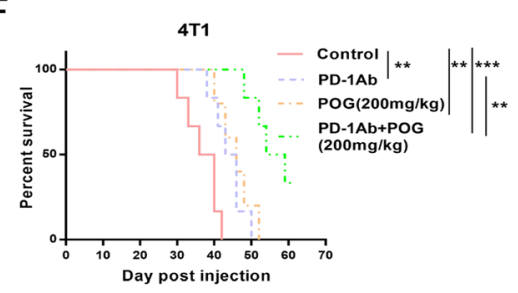

G

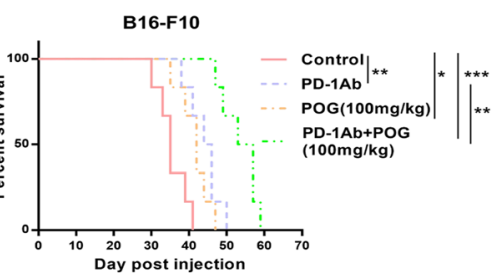

$\mathrm{H}$

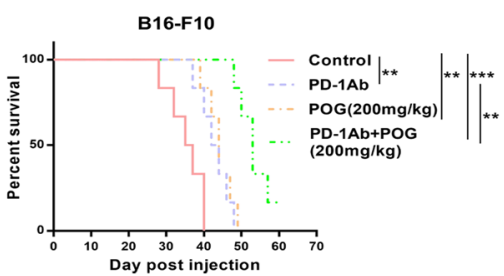

Fig. 7 POG enhances the antitumour effect of PD-1 inhibitor in mouse tumour models of B16-F10 and 4T1. a-B) The tumour growth curves of 4 T1 tumour-bearing mice after POG and anti-PD-1 antibody (alone or in combination) treatment $(n=6)$. $\mathbf{c}$-d The tumour growth curves of $4 \mathrm{~T} 1$ tumour-bearing mice after POG and anti-PD-1 antibody (alone or in combination) treatment $(n=6)$. e-f Survival rate of 4 T1 tumour-bearing mice with POG and anti-PD-1 antibody (alone or in combination) treatment $(n=6) \mathbf{g}$-h Survival rate of B16-F10 tumour-bearing mice with POG and anti-PD-1 antibody (alone or in combination) treatment $(n=6)$. The pooled data from three independent experiments are shown. All data are represented as the mean \pm SD. ${ }^{*} p<0.05,{ }^{* *} p<0.01,{ }^{* *} p<0.001,{ }^{* * *} p<0.0001$

The top 10 key proteins are mainly RNA and ATP binding proteins involved in protein translation, amino acid metabolism and ATP synthesis. Among these proteins, Eprs is an ATP binding protein involved in the metabolism of L-glutamate and L-proline, Dld is an E3 component of the three alpha-ketoacid dehydrogenase complexes with electron transfer activity, and Atp5po participates in the synthesis of ATP $[33,34]$.

Finally, we found that POG could bind well to the key proteins in these pathways, inhibit B16-F10 primary tumour growth and improve the immunosuppressive microenvironment of B16-F10 tumour-bearing mice. POG is a chromone extracted from Saposhnikovia root [35]. POG has been reported to inhibit the production of TNF $\alpha$, IL-1 $\beta$ and IL- 6 in Raw 264.7 cells by inhibiting the activation of MAPK and NF- $\mathrm{KB}$ signalling pathways and reducing serum TNF $\alpha$, IL-1 $\beta$ and IL-6 in vivo $[36,37]$. In addition, POG could dose-dependently inhibit the expression of iNOS, COX-2 and PGE2 by suppressing the activation of JAK2/STAT3 signalling in vitro and in vivo $[37,38]$.

Mechanically, POG reduces the content of ornithine and citrulline in PMN-MDSCs by inhibiting the expression of Arg-1 and iNOS, which further inhibits polyamine production and the TCA cycle and ultimately inhibits the proliferation, metabolism and immunosuppressive ability of cells $[39,40]$. As mentioned above, MDSCs might have partly limited immune checkpoint inhibitors, and combination therapies increase the response rates of PD-1/PD-L1 inhibitors [41-43]. In the present study, we found that POG treatment enhanced the effect of anti-PD-1 immune 


\section{Appendix}

Table 1 The structure of 10 candidate inhibitors

\begin{tabular}{lllllllllll}
\hline Compounds name & Atp50 & Dld & Eprs & Gart & Hadha & Mrpl4 & Umps & Mrpl13 Paics & Rpl8 \\
\hline & -6.781 & -7.363 & -5.189 & -5.359 & -5.97 & -4.184 & -5.189 & -4.987 & -4.185 & -4.748 \\
& & & & & & & & & &
\end{tabular}

Prim-O-glucosylcimifugin

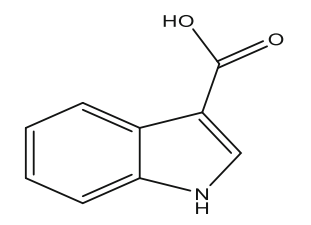

1H-indole-3-carboxylic,acid

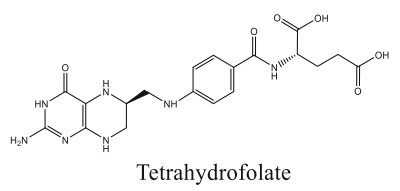

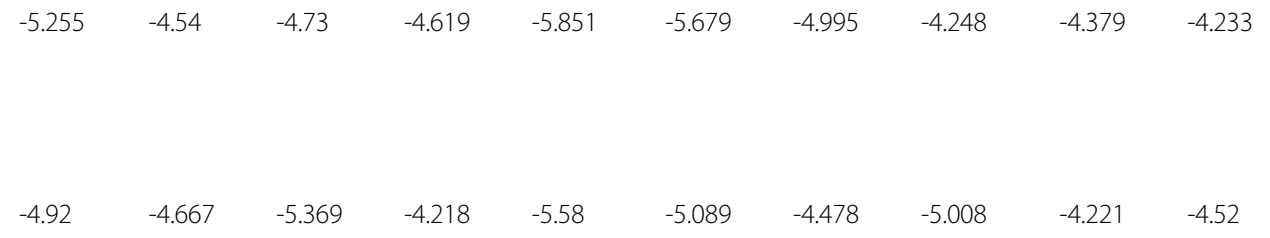
$\begin{array}{llllllllll}-4.92 & -4.667 & -5.369 & -4.218 & -5.58 & -5.089 & -4.478 & -5.008 & -4.221 & -4.52\end{array}$<smiles>O=C(/C=C/c1ccc(O)c(O)c1)c1ccc(O)c(O)c1O</smiles>

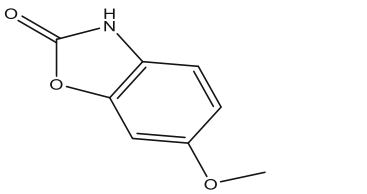

$\begin{array}{llllllllll}-4.588 & -4.085 & -4.408 & -4.691 & -5.101 & -4.375 & -4.682 & -5.208 & -5.517 & -4.324\end{array}$

6-methoxy-2-benzoxazolinone<smiles>Cc1c(C(=O)c2ccccc2C#N)cc(O)c(C=O)c1O</smiles><smiles>O=C1c2ccccc2C(=O)c2cc(O)ccc21</smiles>
$\begin{array}{llllllllll}-4.465 & -5.814 & -5.219 & -4.761 & -4.96 & -4.089 & -4.01 & -5.333 & -4.105 & -4.152\end{array}$<smiles>OCC1=NC=CC2c3ccccc3NC12</smiles>

1-Hydroxymethyl-beta-carboline<smiles>CO[C@H]1c2ccc(O)cc2OC[C@]1(C)Cc1ccc(O)c(O)c1</smiles>

$-4.042$

$$
-5.414
$$$$
-5.311
$$$$
-4.45
$$$$
-5.003
$$ 
Table 1 The structure of 10 candidate inhibitors (Continued)

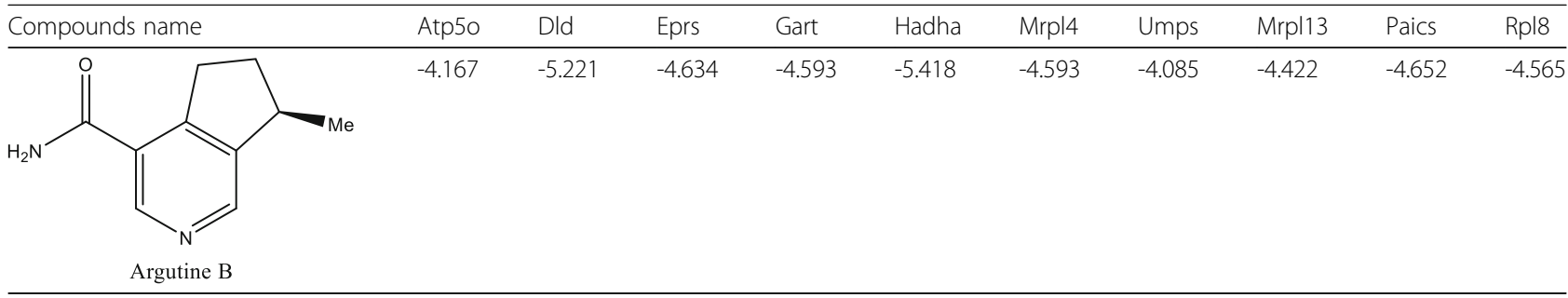

checkpoint blockade in mouse tumour models of B16-F10 and $4 \mathrm{~T} 1$. This result provides a new direction for improving the response rate of PD-1 pathway blockade.

We successfully screened POG from the traditional Chinese Medicine library (20000 compounds) as a PMNMDSC inhibitor. The POG exhibits a good synergistic antitumour effect with PD-1 inhibitors. The synergistic antitumour effect of POG and PD-1 inhibitors offers a reasonable basis for future clinical combination therapy of POG and PD-1 inhibitors to overcome the low response rate and recurrence of $\mathrm{PD}-1$ in clinical practise.

\section{Additional files}

Additional file 1: The structures of the traditional Chinese medicines from TCM Database@Taiwan. (SDF 93000 kb)

\section{Acknowledgements}

We would like to thank Professor Wei Sheng of the H. Lee Moffitt Cancer Research Center of the University of South Florida for technical support and the State Key Laboratory of Medicinal Chemistry Biology of Nankai University for assistance with the instrument platform.

\section{Authors' contributions}

TS, CY, HJL and WFG developed the original hypothesis and experimental design. WFG, XYZ, WDY, DLD, JM, YRL, LY and SC performed the experiments. WFG, HZ, YHT, WLZ and YB performed the data analysis. WFG and $X Y Z$ wrote the manuscript. All read and approved the final manuscript.

\section{Funding}

National Natural Science Funds of China (Grant nos. 81572838, 81872374, 81703581, 81871972), Tianjin Science and Technology Project (Grant nos. 15PTGCCX00140, 18PTSYJC00060), the Chinese National Major Scientific and Technological Special Project for "Significant New Drugs Development" (Grant nos. 2018ZX09736-005, SQ2018ZX090201), the National Key Research and Development Program of China (Grant no. 2018YFA0507203), Postdoctoral support scheme for innovative talents (Grant no. BX20180150), the Chinese Postdoctoral Science Foundation (Grant no. 2018 M640228), and the Fundamental Research Funds for the Central Universities, Nankai University.

\section{Availability of data and materials}

All datasets used and/or analysed during the current study are available from the corresponding author on reasonable request.

\section{Ethics approval and consent to participate}

The present study was approved by the Animal Ethics Committee of the Tianjin International Joint Academy of Biotechnology and Medicine.

\section{Consent for publication}

Not applicable.
Competing interests

The authors declare that they have no competing interests.

\section{Author details}

${ }^{1}$ State Key Laboratory of Medicinal Chemical Biology and College of Pharmacy, Nankai University, Haihe Education Park, 38 Tongyan Road, Tianjin 300353, China. ${ }^{2}$ College of Life Sciences, Nankai University, Tianjin, China.

${ }^{3}$ Tianjin Key Laboratory of Early Druggability Evaluation of Innovative Drugs and Tianjin Key Laboratory of Molecular Drug Research, Tianjin International Joint Academy of Biomedicine, Tianjin, China. ${ }^{4}$ Department of Experimental Facility, State Key Laboratory of Medical Chemical Biology, Nankai University, Tianjin, China. ${ }^{5}$ Academy of Mathematics and Systems Science, Chinese Academy of Sciences School of Economics and Management, University of Chinese Academy of Sciences, Beijing, China.

Received: 5 December 2018 Accepted: 11 July 2019

Published online: 28 August 2019

\section{References}

1. Chen L, Han X. Anti-PD-1/PD-L1 therapy of human cancer: past, present, and future. J Clin Invest. 2015;125:3384-91.

2. Zaretsky JM, Garcia-Diaz A, Shin DS, Escuin-Ordinas H, Hugo W, HuLieskovan S, Torrejon DY, Abril-Rodriguez G, Sandoval S, Barthly L, et al. Mutations associated with acquired resistance to PD-1 blockade in melanoma. N Engl J Med. 2016;375:819-29.

3. Polk A, Svane IM, Andersson M, Nielsen D. Checkpoint inhibitors in breast cancer - current status. Cancer Treat Rev. 2018;63:122-34.

4. Ostrand-Rosenberg S. Myeloid-derived suppressor cells: more mechanisms for inhibiting antitumor immunity. Cancer Immunol Immunother. 2010;59: 1593-600.

5. Ferris RL. Immunology and immunotherapy of head and neck Cancer. J Clin Oncol. 2015;33:3293-304.

6. Trivedi S, Rosen CA, Ferris RL. Current understanding of the tumor microenvironment of laryngeal dysplasia and progression to invasive cancer. Curr Opin Otolaryngol Head Neck Surg. 2016;24:121-7.

7. Filipazzi $P$, Huber $V$, Rivoltini L. Phenotype, function and clinical implications of myeloid-derived suppressor cells in cancer patients. Cancer Immunol Immunother. 2012;61:255-63.

8. Condamine T, Gabrilovich DI. Molecular mechanisms regulating myeloidderived suppressor cell differentiation and function. Trends Immunol. 2011; 32:19-25.

9. Gabrilovich DI, Nagaraj S. Myeloid-derived suppressor cells as regulators of the immune system. Nat Rev Immunol. 2009;9:162-74.

10. Bunt SK, Yang L, Sinha P, Clements VK, Leips J, Ostrand-Rosenberg S. Reduced inflammation in the tumor microenvironment delays the accumulation of myeloid-derived suppressor cells and limits tumor progression. Cancer Res. 2007;67:10019-26.

11. Allavena P, Sica A, Solinas G, Porta C, Mantovani A. The inflammatory microenvironment in tumor progression: the role of tumor-associated macrophages. Crit Rev Oncol Hematol. 2008;66:1-9.

12. Sawanobori Y, Ueha S, Kurachi M, Shimaoka T, Talmadge JE, Abe J, Shono Y, Kitabatake M, Kakimi K, Mukaida N, Matsushima K. Chemokine-mediated rapid turnover of myeloid-derived suppressor cells in tumor-bearing mice. Blood. 2008;111:5457-66.

13. Ostrand-Rosenberg S, Sinha P. Myeloid-derived suppressor cells: linking inflammation and cancer. J Immunol. 2009;182:4499-506.

14. Munn DH, Bronte V. Immune suppressive mechanisms in the tumor microenvironment. Curr Opin Immunol. 2016;39:1-6. 
15. Noman MZ, Desantis G, Janji B, Hasmim M, Karray S, Dessen P, Bronte V, Chouaib S. PD-L1 is a novel direct target of HIF-1alpha, and its blockade under hypoxia enhanced MDSC-mediated T cell activation. J Exp Med. 2014:211:781-90.

16. Ridder K, Sevko A, Heide J, Dams M, Rupp AK, Macas J, Starmann J, Tjwa M, Plate $\mathrm{KH}$, Sultmann $\mathrm{H}$, et al. Extracellular vesicle-mediated transfer of functional RNA in the tumor microenvironment. Oncoimmunology. 2015;4:e1008371.

17. Shojaei F, Wu X, Qu X, Kowanetz M, Yu L, Tan M, Meng YG, Ferrara N. G CSF-initiated myeloid cell mobilization and angiogenesis mediate tumor refractoriness to anti-VEGF therapy in mouse models. Proc Natl Acad Sci U S A. 2009;106:6742-7.

18. Tartour E, Pere H, Maillere B, Terme M, Merillon N, Taieb J, Sandoval F, Quintin-Colonna F, Lacerda K, Karadimou A, et al. Angiogenesis and immunity: a bidirectional link potentially relevant for the monitoring of antiangiogenic therapy and the development of novel therapeutic combination with immunotherapy. Cancer Metastasis Rev. 2011;30:83-95.

19. Dennis G Jr, Sherman BT, Hosack DA, Yang J, Gao W, Lane HC, Lempicki RA. DAVID: database for annotation, visualization, and integrated discovery. Genome Biol. 2003;4:P3.

20. da Huang W, Sherman BT, Lempicki RA. Systematic and integrative analysis of large gene lists using DAVID bioinformatics resources. Nat Protoc 2009;4:44-57.

21. Franceschini A, Szklarczyk D, Frankild S, Kuhn M, Simonovic M, Roth A, Lin J, Minguez $P$, Bork $P$, von Mering C, Jensen LJ. STRING v9.1: protein-protein interaction networks, with increased coverage and integration. Nucleic Acids Res. 2013:41:D808-15.

22. Chen CY. TCM database@Taiwan: the world's largest traditional Chinese medicine database for drug screening in silico. PLoS One. 2011;6: e15939.

23. Sanderson K. Databases aim to bridge the east-west divide of drug discovery. Nat Med. 2011;17:1531.

24. Welte T, Kim IS, Tian L, Gao X, Wang H, Li J, Holdman XB, Herschkowitz $J$, Pond A, Xie G, et al. Oncogenic mTOR signalling recruits myeloidderived suppressor cells to promote tumour initiation. Nat Cell Biol. 2016;18:632-44

25. Zhao X, Rong L, Zhao X, Li X, Liu X, Deng J, Wu H, Xu X, Erben U, Wu P, et al. TNF signaling drives myeloid-derived suppressor cell accumulation. J Clin Invest. 2012:122:4094-104.

26. Kim KO, Lee D, Hiep NT, Song JH, Lee HJ, Lee D, Kang KS. Protective effect of phenolic compounds isolated from Mugwort (Artemisia argyi) against contrast-induced apoptosis in kidney epithelium cell line LLC-PK1. Molecules. 2019:24:195.

27. Burgos-Barragan G, Wit N, Meiser J, Dingler FA, Pietzke M, Mulderrig L, Pontel LB, Rosado IV, Brewer TF, Cordell RL, et al. Mammals divert endogenous genotoxic formaldehyde into one-carbon metabolism. Nature. 2017;548:549-54.

28. Hou Y, Li G, Wang J, Pan Y, Jiao K, Du J, Chen R, Wang B, Li N. Okanin, effective constituent of the flower tea Coreopsis tinctoria, attenuates LPSinduced microglial activation through inhibition of the TLR4/NF-kappaB signaling pathways. Sci Rep. 2017;7:45705.

29. Amen Y, Arung ET, Afifi MS, Halim AF, Ashour A, Fujimoto R, Goto T, Shimizu K. Melanogenesis inhibitors from Coix lacryma-jobi seeds in B16F10 melanoma cells. Nat Prod Res. 2017;31:2712-8.

30. Chou TC. Theoretical basis, experimental design, and computerized simulation of synergism and antagonism in drug combination studies. Pharmacol Rev. 2006;58:621-81.

31. Talmadge JE, Gabrilovich DI. History of myeloid-derived suppressor cells. Nat Rev Cancer. 2013;13:739-52.

32. Trikha $\mathrm{P}$, Carson WE 3rd. Signaling pathways involved in MDSC regulation. Biochim Biophys Acta. 1846;2014:55-65.

33. Mendes MI, Gutierrez Salazar M, Guerrero K, Thiffault I, Salomons GS, Gauquelin L, Tran LT, Forget D, Gauthier MS, Waisfisz Q, et al. Bi-allelic mutations in EPRS, encoding the Glutamyl-prolyl-aminoacyl-tRNA Synthetase, cause a Hypomyelinating Leukodystrophy. Am J Hum Genet. 2018;102:676-84.

34. Johnson MT, Yang HS, Magnuson T, Patel MS. Targeted disruption of the murine dihydrolipoamide dehydrogenase gene (Dld) results in perigastrulation lethality. Proc Natl Acad Sci U S A. 1997;94:14512-7.

35. Dai J, Chen X, Cheng W, Liu X, Fan X, Shen Z, Bi K. A sensitive liquid chromatography-mass spectrometry method for simultaneous determination of two active chromones from Saposhnikovia root in rat plasma and urine. J Chromatogr B Analyt Technol Biomed Life Sci. 2008;868:13-9.
36. Chen N, Wu Q, Chi G, Soromou LW, Hou J, Deng Y, Feng H. Prime-Oglucosylcimifugin attenuates lipopolysaccharide-induced acute lung injury in mice. Int Immunopharmacol. 2013;16:139-47.

37. Zhou J, Sun YY, Sun MY, Mao WA, Wang L, Zhang J, Zhang H. PrimO-glucosylcimifugin attenuates Lipopolysaccharideinduced inflammatory response in RAW 264.7 macrophages. Pharmacogn Mag. 2017;13:378-84

38. Wu LQ, Li Y, Li YY, Xu SH, Yang ZY, Lin Z, Li J. Antinociceptive effects of prim-O-Glucosylcimifugin in inflammatory nociception via reducing spinal COX-2. Biomol Ther (Seoul). 2016;24:418-25.

39. Davel LE, Jasnis MA, de la Torre E, Gotoh T, Diament M, Magenta G, Sacerdote de Lustig E, Sales ME. Arginine metabolic pathways involved in the modulation of tumor-induced angiogenesis by macrophages. FEBS Lett. 2002;532:216-20.

40. Raber P, Ochoa AC, Rodriguez PC. Metabolism of L-arginine by myeloidderived suppressor cells in cancer: mechanisms of T cell suppression and therapeutic perspectives. Immunol Investig. 2012;41:614-34.

41. Tsai KK, Zarzoso I, Daud AI. PD-1 and PD-L1 antibodies for melanoma. Hum Vaccin Immunother. 2014;10:3111-6.

42. Mahoney KM, Freeman GJ, McDermott DF. The next immune-checkpoint inhibitors: PD-1/PD-L1 blockade in melanoma. Clin Ther. 2015;37:764-82.

43. Ohaegbulam KC, Assal A, Lazar-Molnar E, Yao Y, Zang X. Human cancer immunotherapy with antibodies to the PD-1 and PD-L1 pathway. Trends Mol Med. 2015;21:24-33.

\section{Publisher's Note}

Springer Nature remains neutral with regard to jurisdictional claims in published maps and institutional affiliations.

\section{Ready to submit your research? Choose BMC and benefit from:}

- fast, convenient online submission

- thorough peer review by experienced researchers in your field

- rapid publication on acceptance

- support for research data, including large and complex data types

- gold Open Access which fosters wider collaboration and increased citations

- maximum visibility for your research: over $100 \mathrm{M}$ website views per year

At BMC, research is always in progress.

Learn more biomedcentral.com/submission 